\title{
PHASE SCHEDULE IMPLEMENTATION AND THE IMPACT FOR SUBCONTRACTORS
}

\author{
Flora Seixas Ribeiro ${ }^{1}$, Dayana Bastos Costa ${ }^{2}$, and Pedro Antunes Magalhães ${ }^{3}$
}

\begin{abstract}
The hiring of subcontractors for construction is widely adopted in the construction industry, so a good relationship between the subcontractors and contractors is essential for the success of the project. However, there is still a need to analyze how the subcontractors can improve their performance based on a collaborative planning process and their relationship with all participants in the project. This paper aims to discuss the impact of the Phase Schedule in the production planning and control focusing on the subcontractor's viewpoint and how this process assists their performance and participation. To do that, an in-depth case study was developed from April to November 2016, involving the implementation of the Last Planner System focusing on the Phase Schedule technique, including cycles of monitoring through performance measures, as well as data collection through interviews, focusing on the perception of subcontractor's and contractor's concerning the impact of using Phase Scheduling in the planning process. The results show the reinforcement of teamwork and the sense of collaboration identified during the implementation lead to a positive participation and performance of the subcontractors in the Phase Schedule planning process.
\end{abstract}

Keywords: Last Planner System, Phase Schedule, Subcontractor, Collaboration.

\section{INTRODUCTION}

Rahman et al. (2014) argue that the project participants understand that sharing of knowledge and information is one of the key elements of a successful contractual relationship. Manu et al. (2015) state that to achieve success in future projects, a trustbased collaborative environment is required to facilitate high levels of information sharing and to secure commitments of the supply chain from the very early stages of a project. Therefore, communication with, support and training of the subcontractors are important factors in the project environment (Jang et al., 2007).

On the other hand, Lordsleem (2002) argues that there is a difficulty for the subcontractors to achieve the goals of production planning imposed by the contractors, because most of the time, they do not participate in the discussions about the work flow and duration of the activities in an earlier stage. Thus, the Phase Schedule can be an alternative technique to improve the relationship between the team involved in each phase of the project.

The Phase Schedule is a level of planning in the Last Planner System which is the link between work structuring and production control (Ballard and Howell 2003). It is a collaborative planning process where project performers work together to design the

\footnotetext{
Civil Engineer, Master Student, Graduate Program in Civil Engineering, Federal University of Bahia, Salvador, Bahia, Brazil, floraseixasribeiro@gmail.com

2 Associate Professor, Graduate Program in Civil Engineering, Federal University of Bahia, dayanabcosta@ufba.br

3 Civil Engineer, Federal University of Bahia, Salvador, Bahia, pedroamagalhaes@hotmail.com
} 
process to deliver a milestone (Tsao et al. 2014). Ballard and Howell (2003) indicate that the Phase Schedule proposal is to integrate long-term and short-term planning by generating inputs for medium-term planning and consequently increasing its efficiency.

To achieve the Phase Schedule's goals, active participation of the subcontractors has fundamental importance, since the collaboration to develop the plans and the transparency of the information for all involved can contribute to a better work flow and more reliable plans. While studies have been focused on the process and benefits of the Phase Schedule, little is known about how this planning process influences the practices and performance of the subcontractors in the project. Therefore, the main objective of this paper is to understand the impact of the Phase Schedule on the subcontractor's practices and how this process assists the performance and participation of the subcontractors in the project. A single in-depth case study was carried out to achieve this objective.

\section{PHASE SCHEDULE PLANNING LEVEL}

According to Ballard and Tommelein (2016), Phase Schedule has the functions of specify handoffs and conditions of satisfaction between processes within phases. Ballard (2000) argues that Phase Schedule is collaborative planning between the team that will do the work in the phase that extends through the lookahead window. It uses the technique of a pull planning, which is also a part of LPS, and it is used to develop a plan for doing work at any level of task breakdown (Ballard and Tommelein, 2016). This planning is used to develop a more detailed work plan that specifies the handoffs between the specialists involved in that phase (Ballard and Howell, 2003), then each assignment is subjected to constraint's analysis to determine what must be done to make it ready to be executed (Ballard 2000). It encourages project performers to have earlier conversations about how to handle physical interfaces and constraints between components (Tsao et al. 2014).

The main findings identified by Knapp et al. (2006), which involve several Phase Schedule sessions, indicated that the teams involved understood better their project, their individual roles and what was required for success on the project better. Hamzeh et al. (2008) affirm that it is important to employ collaborative Phase Schedule to incorporate inputs from all the project stakeholders in the lookahead process and then it becomes more reliable. Kalsaas et al. (2009) observed that it is relevant the participation of the subcontractor's site representative in the Phase Schedule meetings.

Two of the methods and metrics used to analyze countermeasures to prevent reoccurrence are Percentage of Constraints Removal (PCR), which is the number of constraints removed with the total number of identified constraints, expressed by a percentage and Percentage of Plan Completed (PPC), which is the number of planned activities completed with the total number of activities planned, expressed as a percentage, and the causes of non-compliance of the activities related to the non-removal of the constraints and activities planned.

\section{RESEARCH METHOD}

The case study was developed during the construction of a clinic facility, from April to November 2016, located in the city of Salvador, Bahia, Brazil. This was the first and only experience of the general contractor with the Phase Schedule technique over the period of this study. The project team had already used elements of the LPS, such as visual 
controls, daily huddles, analysis of breakdowns and PPC metric. The definition of the subcontractor in the project was made by the owner and general contractor.

The implementation of the Phase Schedule was undertaken through trainings, Phase Schedule meetings and the monitoring of the implementation through performance measures. These meetings were attended by the project engineering team, subcontractors and the research team. A total of five cycles of Phase Schedule implementation and monitoring was developed during this period. The following construction phases were involved: foundation, structure, masonry, electrical and plumbing installation, facade, ceiling plaster board and drywall system. The meetings occurred at the construction site and lasted for an average of two hours, except the last one that lasted in one hour, probably because of the learning effect of those involved.

As the focus of this paper is the understanding and the evaluation of the impact of the subcontractor due to the Phase Schedule implementation, sources of evidence were used for this analysis, including interviews, results of the performance measures, document analysis and participant observation. The interviews were carried out in order to understand the perception of the subcontractor and general contractor. Questions related to the training and pre-discussion for the Phase Schedule meetings, the development of meetings and the planning and monitoring of the constraints and activities, and difficulties, benefits and feedback for continuous improvement were posed.

A total of four subcontractors involved in the Phase Schedule implementation were interviewed, including the formwork subcontractor, the rebar subcontractor, both for foundation and structure service, the electrical and plumbing installation subcontractor, the ceiling plaster board and drywall system subcontractor. In addition, to gain the contractor's view point, the foreman and the project engineer were interviewed.

The results of the performance measures were used to evaluate the direct impacts that such implementation had on the performance of the subcontractors. The following measures were used as main source of quantitative data: PCR and PPC. This data was collected through the monitoring of the constraints and activities planned in the Phase Schedule meetings, which were supervised by the managers from the project using worksheets during the lookahead and the weekly work plan meetings.

The participatory observation occurred during the Phase Schedule meetings and along with the monitoring of the constraints and planned activities. During the Phase Schedule meetings, it was possible to qualitatively evaluate the interaction and participation of all those involved. In the monitoring of the constraints and planned activities, it was possible to analyze if the constraints identified during the meetings were sufficient to make the activity ready to be executed and if the activities planned were in the right sequence and duration of execution. This data was analyzed in an integrated way with the interview in order to gain a better understanding of the effectiveness of the process and impacts on the subcontractors.

To make the data analysis more objective, two constructs were defined as following:

a) Subcontractors Performance: aims to evaluate to what extent the subcontractors were able to meet the activities planned and to keep to their commitment to remove the constraints that could interfere in their tasks or subsequent tasks. The main source of evidence used was direct observation, data analysis of the worksheets and measures results, as well as interviews.

b) Subcontractor Participation: aimed to evaluate their involvement and learning with the Phase Schedule practices and their participation in the discussion before and during Phase Schedule meeting in order to reach the goals established by the 
master plan. The main source of evidence used was direct observation, and interviews.

\section{RESULTS AND DISCUSSION}

\subsection{Implementation of the Last Planner System focusing on the Phase Schedule}

The implementation of the Last Planner System with focus on the Phase Schedule started with the phase analysis from the master plan in which the milestones were defined by the general contractor. In the Phase Schedule meeting, the activities were planned using the "back to forward" technique, starting from the milestone initially defined. This planning seeks to identify in each activity its constraints, execution duration, the start date and the team required to do the work. The formalization of this planning happened by transferring all the information to a worksheet for the monitoring of the constraints and activities planned. This planning control of activities takes place during the lookahead plan and weekly plan meetings. The weekly plans were discussed with the foreman and sometimes with subcontractors.

\subsection{Results of Indicators: PPC and PCR}

The results obtained by the indicator of Percentage of Constraints Removal (PCR) are shown in the Figure 1, in which the axis are the percentage and the construction phases analyzed in the Phase Schedule meetings. This figure expresses the percentage of each subcontractor's and contractor's constraints that should be eliminated compared with the percentage that actually was eliminated, calculated by the PCR.

The number of constraints at the Foundation phase was lower than the other phases, so it was easier for monitoring the lookahead plan, resulting in a $100 \%$ of the PCR. Unlike the Foundation phase, the Structure phase had few constraints not removed, and the main causes were related to the delay of the material supply, lack of labour force from the rebar subcontractor and changes of plan from the contractor.

To Ballard and Tommelein (2016), it is important to identify the departments and individuals who will be the go-to guys for each type of constraint, thus most of the constraints identified on the Phase Schedule implementation were the responsibility of the general contractor; however, the subcontractor's constraints also had strong influence on the overall performance. For instance, in the Masonry Phase Schedule meeting, the electrical and plumbing installation subcontractor was responsible for only $3 \%$ of the constraints. However, due to the fact the electrical and plumbing subcontractor was hired late, this affected his ability to meet the deadlines established and to remove his constraints, causing a major change of plans. This change-over caused a non-removal of several constraints assigned for the general subcontractors, affecting the PCR result. The change of plans also influenced in the Facade phase, causing a non-removal of the contractor's constraints.

Another issue identified during the monitoring of the constraints from the Drywall/Ceiling Plaster Board phase was that some of the contractor's and electrical and plumbing's constraints were in fact from predecessor activities; so, this required a new analysis for better definition and detailing of the activity. 


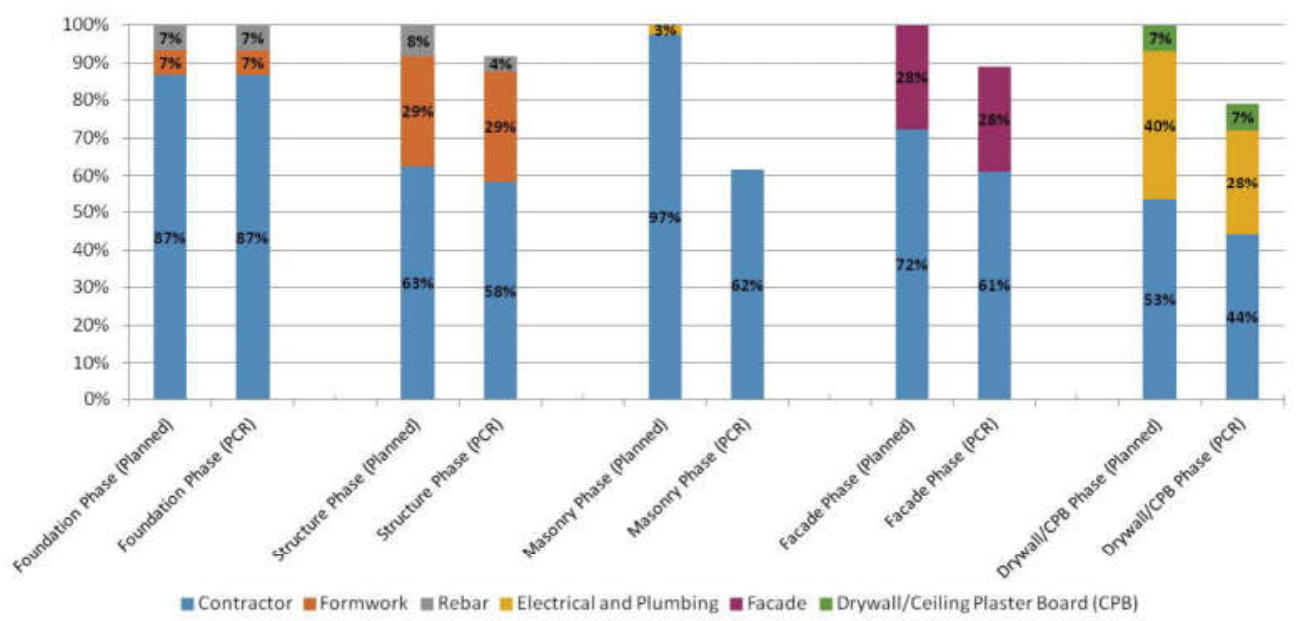

Figure 1 - Percentage of Constraint Removed (PCR) by construction phases analyzed in the Phase Schedule meetings

The PPC results from subcontractors and the whole project are presented in Figure 2. The subcontractor's PPC were found by selecting only activities which were their responsibilities. The Phase Schedule meetings occurred in the weeks 1, 6, 15, 20 and 23, as highlighted in the figure.

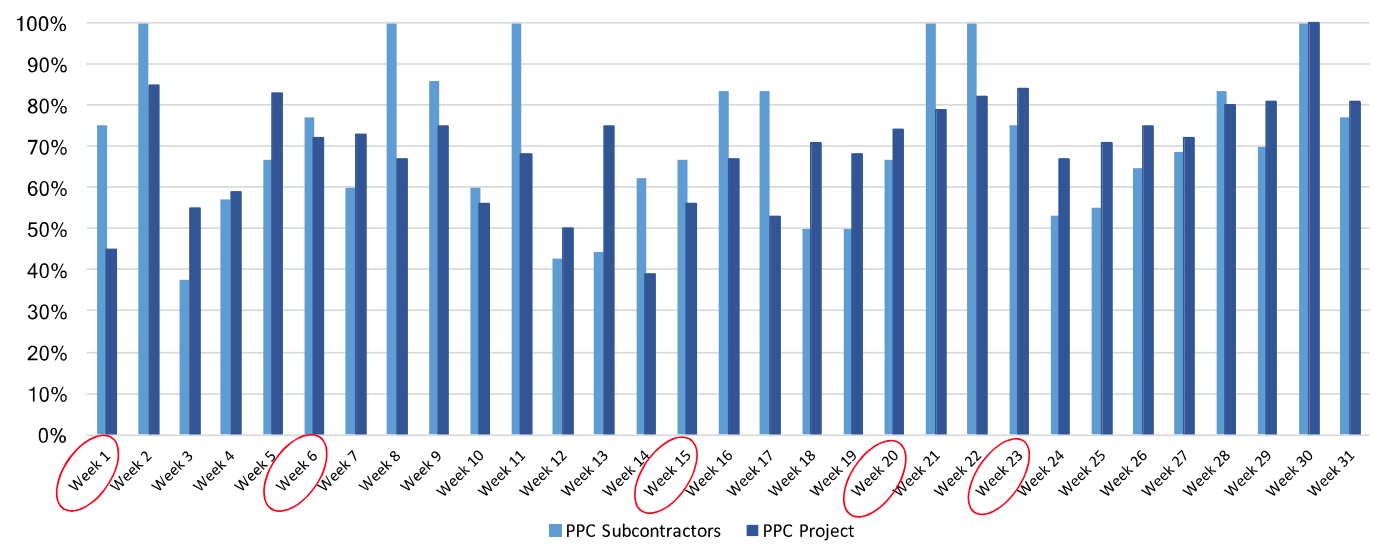

Figure 2 - Percent Plan Completed from Subcontractors and whole project

Based on the weekly PPC result, there is an improvement in the performance of the PPC in the following weeks after the Phase Schedule meetings. This happened probably because those involved had more time to remove the constraints identified. Some Phase Schedule meetings happened in the week before the start date of some activities of the phase, despite the literature which indicates that for the reliability of the planning system, the lead times for acquiring information, materials, labor, and equipment need to be considered (Ballard 2000). However, the main cause of the delay of the definition of the Phase Schedule meeting was the late hiring of the subcontractor by the owner.

The main causes for non-compliance of the activities planned from the weekly PPC were predecessor delay (workflow), change of plans, shift of the teamwork to one service planned to another and lack of subcontractors' commitment. According to this, the main causes of the subcontractors' PPC were predecessor delay (workflow) and change of 
plans. This can indicate that the change of plans at lookahead schedule level has significant impact on the performance of the weekly PPC results.

It is also observed that the average of the subcontractors' results is close to the average of the contractor's, most likely to the general contractor effectiveness for monitoring the subcontractor's constraints and the subcontractors' commitment to accomplish the weekly activities; however, there was a significant difference in the weeks $2,8,11,17,21$ and 22 because the number of subcontractors' activities were much lower than the contractor's. The low results in the weeks 18 and 19 are due to the nonremoval of the electrical and plumbing subcontractor's constraints, causing the noncompliance of the weekly activities.

\subsection{Impacts of the Phase Schedule Implementation on subcontractor's practice, performance and participation}

The main findings of the interviews are presented at Table 1. From the four subcontractors interviewed, only the drywall subcontractor had previous experience with Phase Schedule.

Table 1: Positive aspects and challenges of the Phase Schedule case

\begin{tabular}{|l|l|l|}
\cline { 2 - 3 } \multicolumn{1}{l|}{} & Positive Aspects & Challenges \\
\hline $\begin{array}{l}\text { Training and pre- } \\
\text { discussion }\end{array}$ & $\begin{array}{l}\text { Preparation and pre-discussion of the schedule } \\
\text { and its use as a guide in the Phase Schedule } \\
\text { meetings }\end{array}$ & $\begin{array}{l}\text { Difficulty in visualizing the } \\
\text { method that will be used }\end{array}$ \\
\hline $\begin{array}{l}\text { Phase Schedule } \\
\text { meetings }\end{array}$ & $\begin{array}{l}\text { Support from the engineering team (facilitators) } \\
\text { for a better understanding of the methodology } \\
\text { Transparency because of the visual resources } \\
\text { (post-its and board with the weeks) } \\
\text { Clarification and collaboration of existing } \\
\text { interference and joint identification of constraints } \\
\text { Experiencing the methodology in one meeting } \\
\text { improves the performance in the following ones }\end{array}$ & $\begin{array}{l}\text { Initial difficulty with "back } \\
\text { to forward" planning } \\
\text { discussion at the same } \\
\text { meeting }\end{array}$ \\
\hline $\begin{array}{l}\text { Monout two hours) at the } \\
\text { beginning }\end{array}$ \\
\hline $\begin{array}{l}\text { constraints and } \\
\text { planned activities }\end{array}$ & $\begin{array}{l}\text { Self-reorganization and interactive teamwork at } \\
\text { the field }\end{array}$ & Late hiring of subcontractors \\
\hline
\end{tabular}

In general, the Phase Schedule technique was a new and positive experience that facilitated the development of the field activities. The main positive aspects mentioned by the subcontracts were the improved transparency of information, the opportunity to understand the phase and the possibility of collaboration to identify the best way to execute the task and according to the milestone. These findings corroborate with Kalsaas et al. (2009) study which postulates that this sort of planning process increases the understanding of the tasks for all participants.

The main challenges faced by the subcontractors were the long duration of the meetings in some cases and the high number of activities to be planned. Knapp et al. (2006) highlights that the size and length of the phase selected is very important because when the phase is too large and complex it makes the session less effective.

Concerning the Performance construct, analyzing the PCR and PPC data, the subcontractors achieved good results in both indicators (the average of PCR was $84 \%$ and the average of PPC for subcontractor was $71 \%$ ). These results indicated that the mapping 
of the constrains along the Phase Schedule meetings contributes effectively to a better understanding of possible limitation of the tasks, and addresses issues that need to be resolved before the tasks hit the construction stage (Tsao et al., 2014).

These constraints mapping also contribute to increasing the perception of responsibility of the subcontractor for removing the constraints in order to reduce the uncertainties in the field and to be able to meet the final date planned in the Phase Schedule. However, the late contracting of subcontractors had a direct impact on the ability to meet deadlines (removal of constraints). Ballard and Tommelein (2016) argue that is an area of weakness when specialty contractors are engaged late in the project and do not have sufficient understanding of the work to contribute effectively to planning. Despite this, according to the subcontractors' perception, the monitoring of the activities was well done by the contractors, encouraging them to accomplish the deadlines.

Concerning the participation, the subcontractors presented a low level of resistance related to the adoption of the Phase Schedule practices, such as the pre-discussion, including an improved detailing and duration of the tasks, and throughout the meeting, providing the information required. Also, one good practice identified was related to the sharing of the lessons learned in previous meeting among the participants. It was observed that those who participated in more than one meeting improved their participation at each stage.

The general contractor foreman mentioned in his interview that a greater sense of collaboration in the field was created, reducing the transfer of responsibilities, since everyone was aware of their commitments and the importance of teamwork to reach the goals. The visualization of the whole project during the Phase Schedule meetings facilitates the reorganization of the subcontractors' team in the field, when a delay or uncertainty has happened, without changing the deadline. One advantage of this planning is to create a team able to respond flexibly to differences between assumptions about how the future will turn out and what actually happens (Ballard and Tommelein, 2016).

One of the subcontractors interviewed mentioned that it was very important to have the opportunity to discuss the deadlines of the project in a collaborative way, instead of the traditional package of activities already planned by the general contractors. This highlights the importance of the collaboration characteristic of phase schedule.

\section{CONCLUSIONS AND FUTURE RESEARCH}

This paper aimed to understand the impact of the Phase Schedule in the practices, performance and participation of the subcontractors in the project. Based on the results, the reinforcement of teamwork and the sense of collaboration were identified during the implementation, which was corroborated by the perception of the interviewees. The participants in the meetings expressed their preoccupation to accomplish their agreements established at the Phase Schedule meetings. For instance, when there was a delayed activity which involved more than one subcontractor, they tried to work out solutions together, showing a sense of belonging and responsibility related to the project.

Through the indicators (PCR and PPC) it was possible to understand the performance of the subcontractors from a quantitative perspective. However, there are still opportunities for better definition of measures that could analyze the impact of the Phase

Schedule as a whole to improve the workflow and the reliability of the plan. Also, corroborating with Emdanat and Azambuja (2016), new studies are required which have 
the objective of aligning the short-term work execution planning with the overall Phase Schedule and master schedule targets. A second stage of the present work has been developed to identify measures that can reduce the gap of this knowledge.

\section{REFERENCES}

Ballard, G. (2000). The Last Planner System of Production Control. PhD Diss., University of Birmingham, UK.

Ballard, G., and Howell, G. A. (2003). An Update on Last Planner. 11th Ann. Conf. of the Int'l Group for Lean Construction. [online] Virginia, US. Available at: http://www.iglc.net/Papers/Details/227 [Accessed 05 Dec. 2016].

Ballard, G. \& Tommelein, I. (2016). Current Process Benchmark for the Last Planner System. Available at: p2sl.berkeley.edu [Accessed 03 March. 2017].

Emdanat, S. and Azambuja, M. (2016). Aligning Near and Long Term Planning for LPS Implementations: A Review of Existing and New Metrics. 24th Ann. Conf. of the Int'I Group for Lean Construction. [online] Boston, USA. Available at: http://www.iglc.net/Papers/Details/1253 [Accessed 05 Dec. 2016].

Hamzeh, F. R.; Ballard, G.; and Tommelein I. D. (2008). Improving Construction Work Flow - The Connective Role of Lookahead Planning. 16th Ann. Conf. of the Int'l Group for Lean Construction. [online] Manchester, UK. Available at: http://www.iglc.net/Papers/Details/572 [Accessed 05 Dec. 2016].

Jang, J. W.; Kim, Y.; Park, C. J.; and Jang, W. S. (2007). Importance of Partners in a Challenging Lean Journey. 15th Ann. Conf. of the Int'l Group for Lean Construction. [online] Michigan, USA. Available at: http://www.iglc.net/Papers/Details/496 [Accessed 05 Dec. 2016].

Kalssas, B. T.; Skaar, J.; and Thorstensen, R. T. (2009). Implementation of Last Planner in a Medium-Sized Construction Site. 17th Ann. Conf. of the Int'l Group for Lean Construction. [online] Taipei, Taiwan. Available at: http://www.iglc.net/Papers/Details/433 [Accessed 05 Dec. 2016].

Knapp, S.; Charron, R.; and Howell, G. (2006). Phase Planning Today. 14th Ann. Conf. of the Int'l Group for Lean Construction. [online] Santiago, Chile. Available at: http://www.iglc.net/Papers/Details/433 [Accessed 05 Dec. 2016].

Lordsleem, A. C. Jr. (2002). Metodologia para Capacitação Gerencial de Empresas Subempreiteiras. PHD. Departamento de Engenharia de Construção Civil, Escola Politécnica da Universidade de São Paulo, Universidade de São Paulo, São Paulo. [In portuguese].

Manu, E.; Ankrah, N.; Chinyio, E.; and Proverbs, D. (2015). Trust influencing factors in main contractor and subcontractor relationships during projects. International Journal of Project Management, 33, pp. 1495-1508. http://dx.doi.org/10.1016/j.ijproman.2015.06.006.

Rahman, S. H. A.; Endut, I. R.; Faisol, N.; and Paydar, S. (2014) The Importance of Collaboration in Construction Industry from Contractors' Perspectives. Social and Behavioral Sciences, 129, pp. 414-421. doi: 10.1016/j.sbspro.2014.03.695.

Tsao, C. C. Y.; Draper, J.; and Howell, G. A. (2014). An Overview, Analysis, and facilitation tips for simulations that support and simulate pull planning. 22nd Ann. Conf. of the Int'l Group for Lean Construction. [online] Oslo, Norway. Available at: http://www.iglc.net/Papers/Details/977 [Accessed 05 Dec. 2016]. 